\title{
Interleukin-1 $\beta$ Augments Release of Norepinephrine, Dopamine, and Serotonin in the Rat Anterior Hypothalamus
}

\author{
Futoshi Shintani, ${ }^{1}$ Shigenobu Kanba, ${ }^{1}$ Toshio Nakaki, ${ }^{2}$ Masashi Nibuya, ${ }^{1}$ Norihisa Kinoshita, ${ }^{1}$ Eiji Suzuki, \\ Gohei Yagi, ${ }^{1}$ Ryuichi Kato, ${ }^{2}$ and Masahiro Asai' \\ Departments of 'Neuro-psychiatry and 'Pharmacology, Keio University School of Medicine, Tokyo 160, Japan
}

We investigated the effects of interleukin- $1 \beta$ (IL-1 $\beta$ ), administered directly into the rat anterior hypothalamus (AHY), on monoamine release in the same region by using a brain microdialysis technique and an HPLC-electrochemical detection system. First, to study the local effects of IL-1 $\beta$, we used a microdialysis probe equipped with a microinjection tube for administering IL-1 $\beta$ in the same region into which the probe had been inserted. IL-1 $\beta(1 \mathrm{ng})$ injected directly into the AHY elicited release of norepinephrine (NE), dopamine (DA), and 5-HT, as well as increases in their metabolites, 4-hydroxy-3-methoxyphenylglycol, 3,4-dihydroxyphenylacetic acid, 4-hydroxy-3-methoxyphenylacetic acid, and 5-hydroxyindole-3-acetic acid, in the AHY. Vehicle alone exerted no effect on monoamine release. Although the elevated levels of NE and DA persisted for more than $6 \mathrm{hr}$ after injection of $\mathrm{IL}-1 \beta$, the elevated levels of $5-\mathrm{HT}$ were transient. Second, in order to investigate whether this effect of IL-1 $\beta$ is a direct action in the AHY, we performed in vitro experiments using hypothalamus slices. IL-1 $\beta$ (0.1 and $1 \mathrm{nM})$ increased the levels of each monoamine released from hypothalamic slices in a dose-dependent manner. These findings suggest that $\mathrm{IL-1} \beta$ acts directly on the hypothalamus to induce release of NE, DA, and 5-HT. Third, the roles of prostaglandins (PGs) in NE release in the AHY elicited by direct injection of IL- $1 \beta$ were examined. Indomethacin (INDO; $5 \mathrm{mg} / \mathrm{kg}$ ) was administered intraperitoneally, and then $1 \mathrm{hr}$ later, IL-1 $\beta$ (1 $\mathrm{ng}$ ) was injected directly into the AHY through the microinjection tube. IL-1 $\beta$ was still capable of increasing NE release, although the INDO pretreatment had decreased 6-ketoprostaglandin $F_{1} \alpha$ levels in the rat hypothalamus. Fourth, to exclude the possibility that corticotropin-releasing hormone (CRH) is involved in NE release by IL-1 $\beta$, rats were pretreated with dexamethasone (DXM; $0.3 \mathrm{mg} / \mathrm{kg}$ ), and then NE release in the AHY elicited by IL-1 $\beta$ was measured. IL$1 \beta$ was still capable of inducing NE release, although the DXM pretreatment had decreased blood adrenocorticotropic hormone levels. These findings suggest that IL-1 $\beta$ acts directly on the AHY to augment the release of NE without $P G$ involvement or elevation of CRH levels.

\footnotetext{
Received Dec. 3, 1992; revised Feb. 18, 1993; accepted Mar. 1, 1993.

This work was supported in part by Keio Gijuku Academic Development Funds, a Research Grant for Nervous and Mental Disorders from the Ministry of Health and Welfare, and Ohme Keiyu Hospital (Dr. N. Otsuka).

Correspondence should be addressed to Futoshi Shintani, M.D., Department of Neuro-psychiatry, Keio Lniversity School of Medicine, Shinanomachi 35, Shinjuku-ku, Tokyo 160 , Japan.

Copyright (C) 1993 Society for Neuroscience $0270-6474 / 93 / 133574-08 \$ 05.00 / 0$
}

[Key words: interleukin-1 $\beta$, dopamine, norepinephrine, 5-HT, rat anterior hypothalamus, brain microdialysis, prostaglandin, adrenocorticotropic hormone, corticotropin-releasing hormone, indomethacin, dexamethasone]

Interleukin- $1 \beta(\mathrm{IL}-1 \beta)$ is an important cytokine mediating stimulation of the hypothalamo-pituitary-adrenal (HPA) axis (Tsagarakis et al., 1989; Gwosdow et al., 1990; Besedovsky et al., 1991; Watanobc ct al., 1991). Intracranially infuscd IL-1 $\beta$ induces the release of corticotropin-releasing hormone $(\mathrm{CRH})$ and adrenocorticotropic hormone (ACTH) (Barbanel et al., 1990). Some reports indicate that IL- $1 \beta$ may also be involved in stressinduced reactions (Berkenbosch et al., 1991; Dunn et al., 1991). Recently, it was reported that immobilization stress induced IL$1 \beta$ mRNA in the rat hypothalamus (Minami et al., 1991).

Environmental stressors also activate monoaminergic neurons in the CNS, as well as the HPA axis. Effects of IL-1 $\beta$ on monoamines in the CNS are controversial; Kabiersch et al. (1988) showed that the effects of IL-1 seem to be specific for elevation of 4-hydroxy-3-methoxyphenylglycol (MHPG) since no comparable changes in brain content of dopamine (DA), 5-HT, or 5-hydroxyindole-3-acetic acid (5-HIAA) were detected after administration of IL- 1 . On the other hand, Palazzolo and Quadri (1990) reported that IL- $1 \beta$ promotes in vitro release and prevents blunting catecholamine [norepinephrine (NE) or DA] release from hypothalami in vitro. Dunn and Welch (1991) showed that intraperitoneal injection of IL-1 elevates brain tryptophan, which may reflect increased 5-HT release. Increased release of 5-HIAA and MHPG was observed following systemic administration of IL-1 (Mefford and Heyes, 1990). Recently, Carmelina et al. (1991) showed that intracranioventricularly administered IL$1 \beta$ increased 5-HIAA levels in the anterior hypothalamus (AHY). IL- $1 \beta$ injected into the medial basal hypothalamus has been shown to exert biphasic effects on the release of DA and 3,4dihydroxyphenylacetic acid (DOPAC) from the hypothalamus (Mohankumar et al., 1991).

In order to investigate systematically the monoamine-releasing effects of IL- $1 \beta$ in the rat hypothalamus, first we quantified the extracellular levels of NE, DA, 5-HT, and their metabolites produced in the rat AHY by IL- $1 \beta$, which had been injected directly into the rat $\mathrm{AHY}$, using in vivo brain microdialysis and an HPLC-electrochemical detection system.

Second, we measured the levels of these monoamines released from rat hypothalamus slices in vitro in response to the addition of IL- $1 \beta$, to determine whether any of the IL- $1 \beta$-induced changes were due to direct effects of IL-1 $\beta$ on the AHY.

Third, since some reports have suggested that the increases 


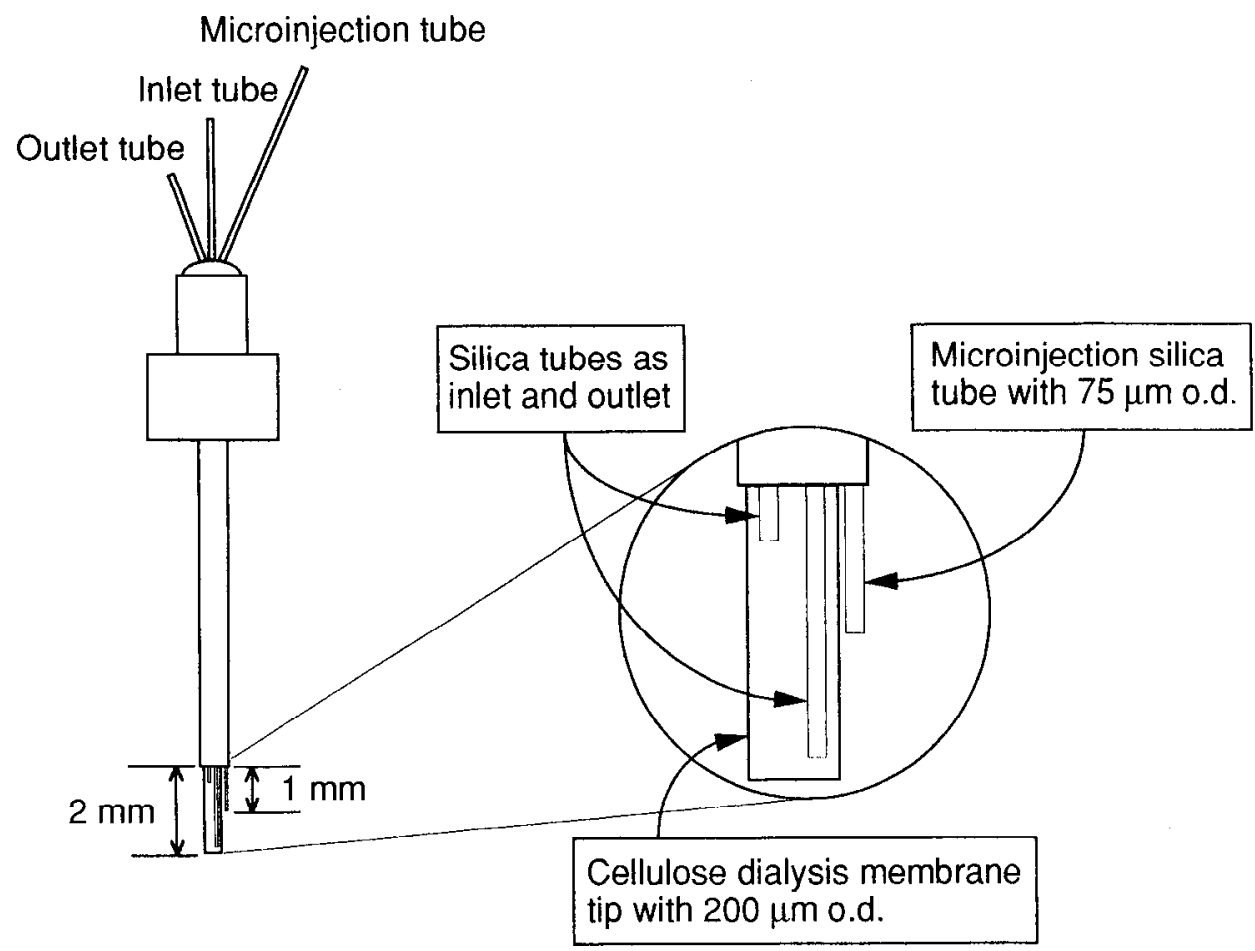

Figure 1. Diagram of the microdialysis probe attached to the microinjection tube. Two silica tubes (inlet and outlet) with $75 \mu \mathrm{m}$ o.d. were placed inside the lumen of the dialysis membrane ( $2 \mathrm{~mm}, 200 \mu \mathrm{m}$ o.d.). Onc microinjection tube with a $75 \mu \mathrm{m}$ o.d. was set up in parallel with these tubes. The microinjection tube is half the length of the dialysis membrane. in NE, DA, and 5-HT release induced by $\mathrm{IL}-1 \beta$ in the hypothalamus are partially mediated by the actions of arachidonic acid metabolites (Masana et al., 1990; Mefford and Heyes, 1990), we used microdialysis to investigate the effects of indomethacin (INDO) on the NE release in the AHY elicited by direct injection of IL-1 $\beta$. We also measured 6-ketoprostaglandin $\mathrm{F}_{1} \alpha$ levels in the rat hypothalamus to provide a positive control for intraperitoneally injected INDO.

Fourth, we administered IL- $1 \beta$ directly into the AHY after the administration of a large amount of dexamethasone (DXM), in order to exclude possible involvement of $\mathrm{CRH}$, known to be induced by IL-1 $\beta$ (Cambronero et al., 1989). We also measured plasma ACTH levels to provide a positive control for intraperitoneally injected DXM.

\section{Materials and Methods}

Animals. Six-week-old male Sprague-Dawley rats were housed in a temperature-controlled room $\left(23-25^{\circ} \mathrm{C}\right)$ under a $12 \mathrm{hr}$ reversed lightdark schedule for 1-2 weeks. Food and water were provided ad libitum throughout the experimental period. A guide shaft was surgically implanted at 7-8 weeks, for use in the microdialysis experiments, which were conducted at 9-11 weeks when the rats weighed $250-320 \mathrm{gm}$. The experiments to measure 6-ketoprostaglandin $F_{1} \alpha$ levels in the hypothalamus and ACTH levels in plasma were performed in 9-11-weekold rats.

Microdialysis probe. The microdialysis probes (Eicom, Kyoto, Japan) were constructed of three stainless steel tubes, two silica tubes (inlet and outlet) with a $75 \mu \mathrm{m}$ o.d. and a microinjection silica tube with a $75 \mu \mathrm{m}$ o.d (Fig. 1). Two silica tubes were inserted inside the lumen of the dialysis membrane ( $2 \mathrm{~mm}, 200 \mu \mathrm{m}$ o.d.), one as an inlet and the other as an outlet. One microinjection tube was placed in parallel with these tubes. The microinjection tube was half the length of the dialysis membrane. These three silica tubes were sealed together with epoxy resin, and each one was secured with stainless steel tubing at the top of the probe.

Surgical procedure. Rats were anesthetized with an intraperitoneal injection of pentobarbital $(12.5 \mathrm{mg} / \mathrm{kg})$. The skull was exposed and a burr hole was drilled. A guide shaft was stereotaxically implanted in the left AHY (1.5 mm posterior to the bregma, $1.0 \mathrm{~mm}$ lateral to the midline, $7.0 \mathrm{~mm}$ below the surface of the skull, according to the atlas of Paxinos and Watson), and fixed to the skull with dental cement held in place by two stainless steel screws. These animals were maintained under the same conditions for at least $10 \mathrm{~d}$ until the initiation of microdialysis. After a microdialysis probe had been carefully inserted through the guide shaft, it was filled with $0.45 \mu \mathrm{m}$ membrane (Micron Separations Inc.)-filtered and degassed Hanks' solution (137 m M NaCl,

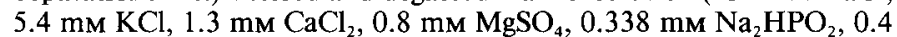
$\mathrm{mm} \mathrm{KH}_{2} \mathrm{PO}_{2}, 5.6 \mathrm{~mm}$ glucose, $\left.4.2 \mathrm{~mm} \mathrm{NaHCO}_{3}, \mathrm{pH} 7.4\right)$. The operated rats were then placed in a plastic cages, where the experiments were to be performed, and allowed to adapt to these conditions for $24 \mathrm{hr}$.

For the experiments to determine 6-ketoprostaglandin $F_{1} \alpha$ levels in the hypothalamus, an operation allowing direct injection of IL- $1 \beta$ into the bilateral AHY was performed. After the rats had been anesthetized, the skull was exposed and a burr hole was drilled. Two sterile (nonpyrogenic) 26 gauge needles were stereotaxically implanted in the bilateral AHY as described above, and fixed to the skull with dental cement held in place by two stainless steel screws. These animals were used for experiments performed between 24 and $48 \mathrm{hr}$ after the operation. After all of the experiments were finished, we confirmed anatomically that the tip of the microdialysis probe or the needle had reached the AHY.

In the case of the blood sampling experiments to determine ACTH levels in plasma, after the rats had been anesthetized as described above, a polyethylene tube, filled with saline including heparin $(50 \mathrm{U} / \mathrm{ml})$, was inserted into the jugular vein by a previously described method (Nakaki et al., 1981). These animals remained under the same conditions until the start of the experiments for 1-2 d.

Microdialysis. After the probe had been perfused with Hanks' solution at a flow rate of $2 \mu \mathrm{l} / \mathrm{min}$ for $3 \mathrm{hr}$ to allow equilibration, sequential 20 min samples were collected into microtubes (Eicom) containing $70 \mu \mathrm{l}$ of acetate water solution $(0.02 \mathrm{~mm})$ to prevent oxidation of catechol compounds. After six baseline fractions had been collected, a 1 or 10 $\mathrm{ng}$ dose of human recombinant IL- $1 \beta$ (endotoxin levels $<100 \mathrm{fg}$ per ng of IL-1 $\beta$; Endogen) dissolved in $2 \mu \mathrm{l}$ of Hanks' solution (including $0.1 \% \mathrm{BSA}$ as a carrier protein) was injected in $2 \mathrm{~min}$ through the microinjection tube into the same region into which the probe had been inserted. Sampling was continued for $5 \mathrm{hr}$ while the microtubes were maintained at $4^{\circ} \mathrm{C}$. As a control, the same volume of vehicle was injected at the same velocity. Each $100 \mu \mathrm{l}$ sample was immediately injected into the HPLC system. Food and water were provided ad libitum throughout the microdialysis.

In the case of experiments utilizing INDO or DXM administration, 
rats were injected intraperitoneally with INDO dissolved in physiological saline with $5 \% \mathrm{Na}_{2} \mathrm{CO}_{3}(5 \mathrm{mg} / \mathrm{kg})$ or with DXM dissolved in physiological saline ( 1 or $10 \mathrm{mg} / \mathrm{dl}, 0.03$ or $0.3 \mathrm{mg} / \mathrm{kg}$ ) or one of the vehicles $(3 \mathrm{ml} / \mathrm{kg}$ ), and dialysis samples were collected every $20 \mathrm{~min}$ for at least $60 \mathrm{~min}$. After three samples had been collected, $1 \mathrm{ng}$ of IL-1 $\beta$ was injected as described above.

HPLC analysis. Dialysis samples were injected into a reverse-phase ion pair HPLC with electrochemical detection for the measurement of NE, MHPG, DA, DOPAC, 4-hydroxy-3-methoxyphenylacetic acid (HVA), 5-HT, and 5-HIAA. The chromatographic system consisted of a dual-plunger pump (EP-10, Eicom), an electrochemical detector with a carbon-graphite electrode (ECD-100, Eicom), an auto-sampling injector (231-401, Gilson Medical Electronics Inc.) with a $100 \mu$ l loop, and an ODS column. We used two kinds of column, CA-5ODS (150 $\mathrm{mm} \times 4.6 \mathrm{~mm}$ i.d.; Eicom) to analyze the levels of $\mathrm{NE}, \mathrm{MHPG}, \mathrm{DA}$, and 5-HT, and MA-ODS (250 $\mathrm{mm} \times 4.6 \mathrm{~mm}$ i.d.; Eicom) to analyze the levels of NE, MHPG, DOPAC, HVA, 5-HT, and 5-HIAA.

The mobile phase consisted of the following: (1) for analysis of NE and $\mathrm{MHPG}, 95 \% 0.1 \mathrm{M}$ phosphate buffer solution (consisting of 0.0862 M NaH $\mathrm{PO}_{4} \cdot 2 \mathrm{H}_{2} \mathrm{O}$ and $0.0138 \mathrm{M} \mathrm{Na}_{2} \mathrm{HPO}_{4} \cdot 12 \mathrm{H}_{2} \mathrm{O} ; \mathrm{pH} 6.0$ ), $5 \%$ methanol, $400 \mathrm{mg} / \mathrm{liter}$ sodium 1 -octanesulfonate (SOS), and $50 \mathrm{mg} / \mathrm{liter}$ ethylenediamine tetraacetic acid $2 \mathrm{Na}$ (EDTA-2Na); (2) for DA and 5-HT, $80 \% 0.1 \mathrm{~m}$ phosphate buffer solution, 20\% methanol, 500-550 $\mathrm{mg} / \mathrm{liter}$ SOS, and $50 \mathrm{mg} / \mathrm{liter}$ EDTA-2Na; (3) for NE, MHPG, DOPAC, HVA, 5-HT, and 5-HIAA, 83-85\% acetate-citrate solution (consisting of $0.0474 \mathrm{M} \mathrm{CH}_{3} \mathrm{COONa}$ and $0.0526 \mathrm{M}$ citric acid; pH 3.5$), 15-17 \%$ methanol, $230 \mathrm{mg} /$ liter SOS, and $5 \mathrm{mg} /$ liter EDTA.2Na. Just before use, the buffer was sonicated to degas. Separation was achieved at $25^{\circ} \mathrm{C}$ using a flow rate of $1 \mathrm{ml} / \mathrm{min}$.

An electrochemical detector with a carbon-graphite working electrode was set at $+550 \mathrm{mV}$ for NE and MHPG, at $+400-450 \mathrm{mV}$ for DA and 5-HT, and at +700-750 mV for NE, MHPG, DOPAC, HVA, 5-HT, and 5-HIAA, versus an $\mathrm{Ag} / \mathrm{AgCl}$ reference electrode. Since MHPG exists mostly as a conjugated form in the rat brain, we could not determine total $\mathrm{MHPG}$ levels with a conventional microdialysis system without treating the samples with a hydrolyzing enzyme such as sulfatase. We were, however, able to detect a putative MHPG peak using two different conditions: (1) a carbon-graphite working electrode set at $+550 \mathrm{mV}$ versus an $\mathrm{Ag} / \mathrm{AgCl}$ reference electrode and 5\% methanol and 95\% 0.1 $M$ phosphate buffer solution including $400 \mathrm{mg} / \mathrm{liter}$ SOS as the mobile phase; (2) a carbon-graphite working electrode set at $+700-750 \mathrm{mV}$ versus an $\mathrm{Ag} / \mathrm{AgCl}$ reference electrode and 15-17\% methanol and 83$85 \%$ acetate-citrate solution including $230 \mathrm{mg} / \mathrm{liter}$ SOS as the mobile phase. Data were recorded on an integrator (chromatocorder 12, JAS$\mathrm{CO}$, Tokyo, Japan), and peak heights/area of dialysis samples were compared with those of standards determined each day for quantification. The detection limit was $0.5-1 \mathrm{pg} / 100 \mu \mathrm{l}$.

Slice experiments. Nine- to eleven-week-old male Sprague-Dawley rats were used for the slice experiments. They were decapitated under light anesthesia with diethylether, and the brain was immediately removed from the skull and placed in cold Hanks' solution to wash the surface. The AHY was dissected out by cutting the brain, stereotaxically, at the optic chiasma rostrally, $2 \mathrm{~mm}$ from the midline laterally, $3 \mathrm{~mm}$ from the optic chiasma caudally, and $2 \mathrm{~mm}$ from the brain bottom dorsally, within 5 min after decapitation. After the resulting cubic block of tissue had been spread on a cold plate and sliced at $300 \mu \mathrm{m}$ intervals, the slices were immediately put into an Eppendorf tube containing 100 $\mu l$ of one of the four reaction solutions [0.1\% BSA-containing Hanks' solution as vehicle, IL- $1 \beta(0.1 \mathrm{nM}, 1 \mathrm{nM})$, or $60 \mathrm{mM} \mathrm{KCl}$ dissolved in $0.1 \% \mathrm{BSA}$ containing Hanks' solution], following washing the surface with Hanks' solution once and $10 \mathrm{~min}$ preincubation, at $37^{\circ} \mathrm{C}$. The reaction was allowed to continue for $10 \mathrm{~min}$. After the reaction tube had been centrifuged $\left(1000 \times g, 3 \mathrm{~min}, 4^{\circ} \mathrm{C}\right)$, the supernatant $(90 \mu \mathrm{l})$ was transferred to another Eppendorf tube containing the same volume of acetate water solution $(0.04 \mathrm{~mm})$ as a sample for monoamine assay, and the precipitate was stored at $-20^{\circ} \mathrm{C}$ until the proteins were assayed (Lowry et al., 1951). One hundred microliter samples filtered through a $0.45 \mu \mathrm{m}$ membrane filter (Micron Separations Inc., Westboro, MA), following centrifugation at $22,000 \times g$ for $10 \mathrm{~min}$, were injected into the HPLC system to determine the levels of NE, MHPG, 5-HT, 5-HIAA, DA, DOPAC, and HVA using the method described above.

6 -Ketoprostaglandin $F_{1} \alpha$ assay. INDO $(5 \mathrm{mg} / \mathrm{kg})$ dissolved in physiological saline with $5 \% \mathrm{Na}_{2} \mathrm{CO}_{3}$ or vehicle $(3 \mathrm{ml} / \mathrm{kg})$ was intraperitoneally administered to one group $(n=8)$ of rats, and the animals were decapitated under light anesthesia $60 \mathrm{~min}$ later. Another group of rats $(n=8)$ was given INDO $(5 \mathrm{mg} / \mathrm{kg})$ or vehicle $(3 \mathrm{ml} / \mathrm{kg})$ intraperitoneally, and $1 \mathrm{ng}$ of IL- $1 \beta$ was injected through 26 gauge needles into the bilateral AHY 60 min later. After another 60 min later the animals were decapitated under light anesthesia. The hypothalami were stereotaxically dissected by immediately removing the brain from the skull, as described for the slice experiments. The hypothalamus was immediately frozen and stored in liquid nitrogen. The levels of 6-ketoprostaglandin $F_{1} \alpha$ in the hypothalamus were determined using a radioimmunoassay kit (Amersham). Variants within assays were less than $5 \%$.

$A C T H$ assay. One milliliter of blood was collected from the jugular vein through a polyethylene tube inserted while a nonanesthetized and tranquil state, and immediately placed in an ice-chilled, EDTA-containing glass tube. Sixty minutes after DXM $(0.3 \mathrm{mg} / \mathrm{kg})$ had been administered intraperitoneally, another $1 \mathrm{ml}$ of blood was collected. Each glass tube containing blood was centrifuged $\left(3000 \times g, 10 \mathrm{~min}, 4^{\circ} \mathrm{C}\right)$, and plasma $(500 \mu 1)$ was transferred to another Eppendorf tube for storage at $-20^{\circ} \mathrm{C}$ until the levels of ACTH were determined using an immunoradiometric assay kit (Nakai et al., 1989). Variants within assays were $3-6 \%$.

Data analysis. Results are presented as the mean \pm SEM. Data were analyzed statistically using a post hoc Dunnetl's $t$ test or Student's $t$ test. $P<0.05$ was considered significant.

\section{Results}

\section{Monoamine kinetics with $I L-1 \beta$ administration}

Basal extracellular levels of NE, MHPG, 5-HT, 5-HIAA, DA, DOPAC, and HVA in the AHY were $2.45 \pm 0.11,17.47 \pm$ $0.43,3.66 \pm 0.26,374.2 \pm 3.47,1.77 \pm 0.17,131.5 \pm 2.63$, and $85.9 \pm 0.92(\mathrm{pg} / 20 \mathrm{~min}$ defined as the mean \pm SEM of the six samples), respectively. IL- $\beta$ administration stimulated release of NE, 5-HT, and DA, and increased their metabolite levels, whereas administration of vehicle ( $2 \mu$ l of Hanks' solution including $0.1 \% \mathrm{BSA}$ ) exerted no significant effects on any of the monoamines or other metabolites (Fig. $2 A, C, E$ ). Increased NE and DA levels were demonstrated immediately after the administration of IL- $1 \beta$ and remained 1.5-2.5 times higher than the basal level. On the other hand, two- to threefold elevations of 5-HT levels appeared only transiently. Metabolite levels also increased in parallel with neurotransmitter levels (Fig. $2 B, D, F, G$ ): MHPG, DOPAC, and HVA by 1.5-2.5 times; 5-HIAA by $1.2-$ 1.5 times. The increased levels of DOPAC, HVA, and 5-HIAA induced by IL- $1 \beta$ were dose dependent. We could not determine the levels of NE, DA, 5-HT, and MHPG, when $10 \mathrm{ng}$ of IL- $1 \beta$ was injected directly into the AIIY, since impure peaks on the chromatograph interfered with their peaks more strongly.

\section{Monoamine release from $A H Y$ slices in vitro}

IL- $1 \beta$ directly caused release of NE, 5-HT, and DA from hypothalamus slices in a dose-dependent manner (Fig. $3 A, C, E$ ). Monoamine release from hypothalamus slices with $0.1 \mathrm{nM}$ IL$1 \beta$ was significantly greater than from those treated with vehicle $(P<0.05, n=4)$. Each amine level stimulated by $1 \mathrm{~nm} \mathrm{IL-1} \beta$ showed a nearly maximal response, not differing significantly from the level of release induced by $60 \mathrm{mM} \mathrm{KCl}$. Levels of all metabolites, MHPG, 5-HIAA, DOPAC, and HVA were also elevated in parallel with the levels of NE, 5-HT, and DA (Fig. $3 B, D, F, G)$, respectively.

\section{Effects of INDO administration on $N E$ release}

As shown in Figure $4 A$, intraperitoneal administration of INDO or vehicle exerted only transient effects on NE release in the AHY. This could be due to mild stress caused by the intraperitoneal injection. When $1 \mathrm{ng}$ of IL- $1 \beta$ was administered directly through the microinjection tube into the AHY at 60 min after INDO or vehicle had been administered, NE release was in- 
A NE
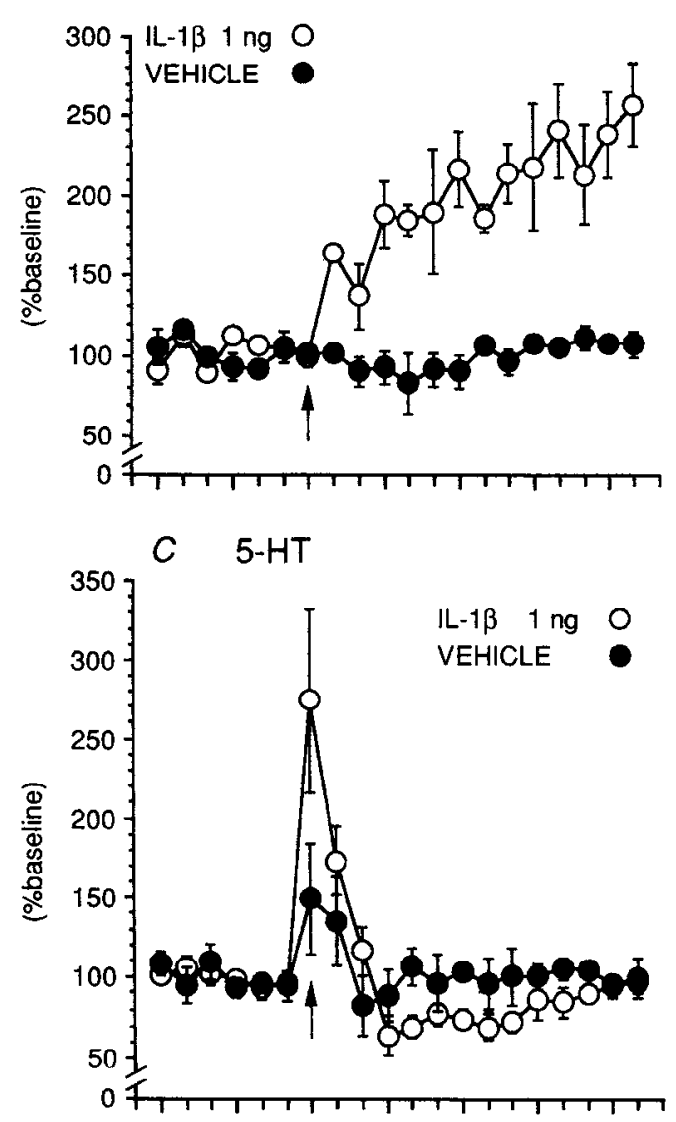

E DA

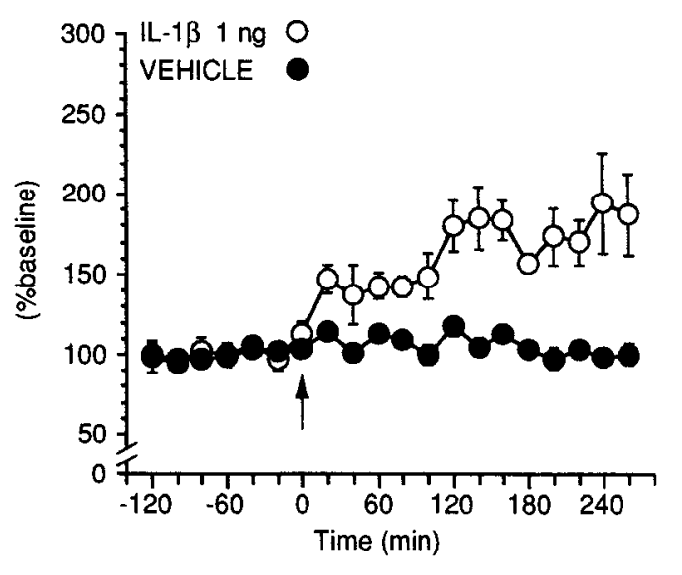

B MHPG

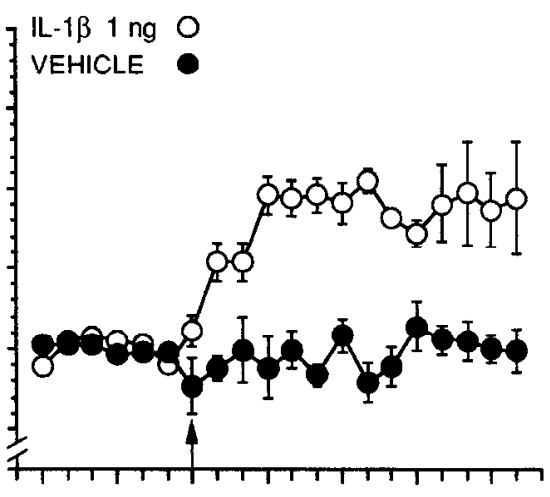

D 5-HIAA

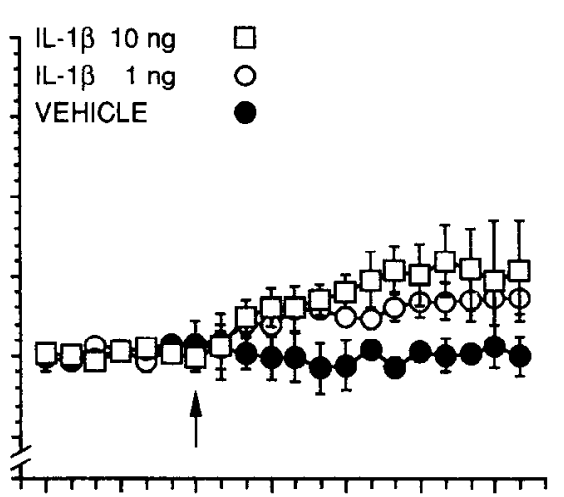

$F$ DOPAC
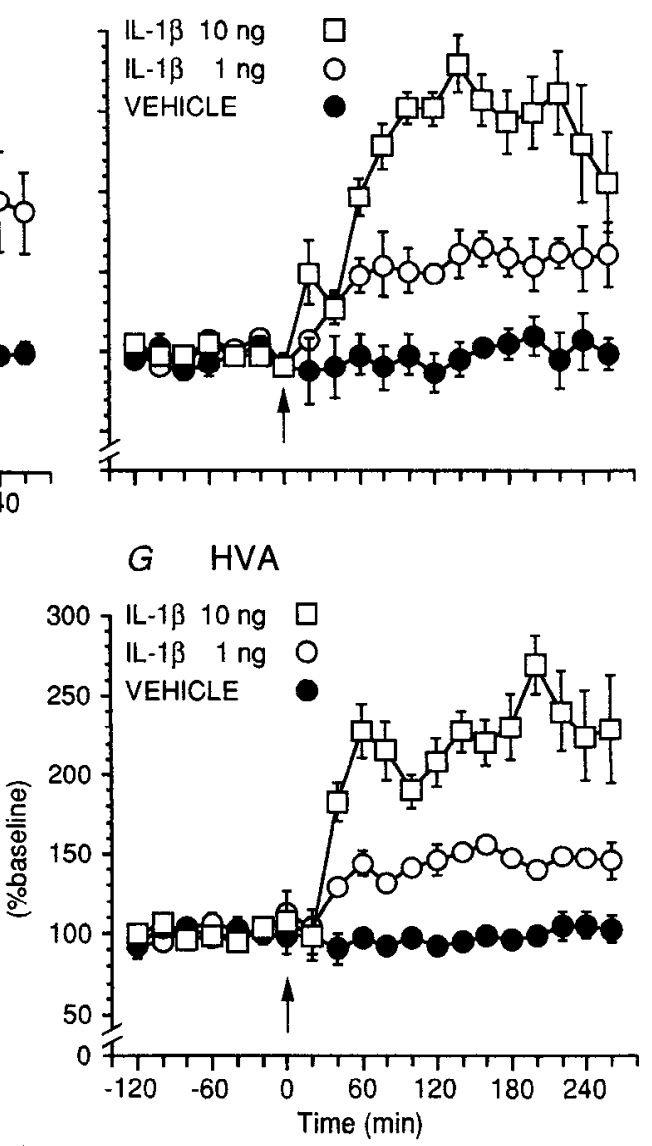

Figure 2. The effects of IL- $1 \beta$ injected into the rat AHY through the microinjection tube on the levels of released NE $(A), \operatorname{MHPG}(B), 5$-HT $(C)$, 5-HIAA $(D)$, DA $(E)$, DOPAC $(F)$, and HVA $(G)$ measured in same region, using microdialysis. Arrows represent the timing of $\mathrm{IL}-\beta$ injection $(10 \mathrm{ng}$, open squares; 1 ng, open circles). Vehicle (solid circles) injected into the same region exerted no significant effects (open circles vs solid circles: $P<0.05, n=6$ ). 

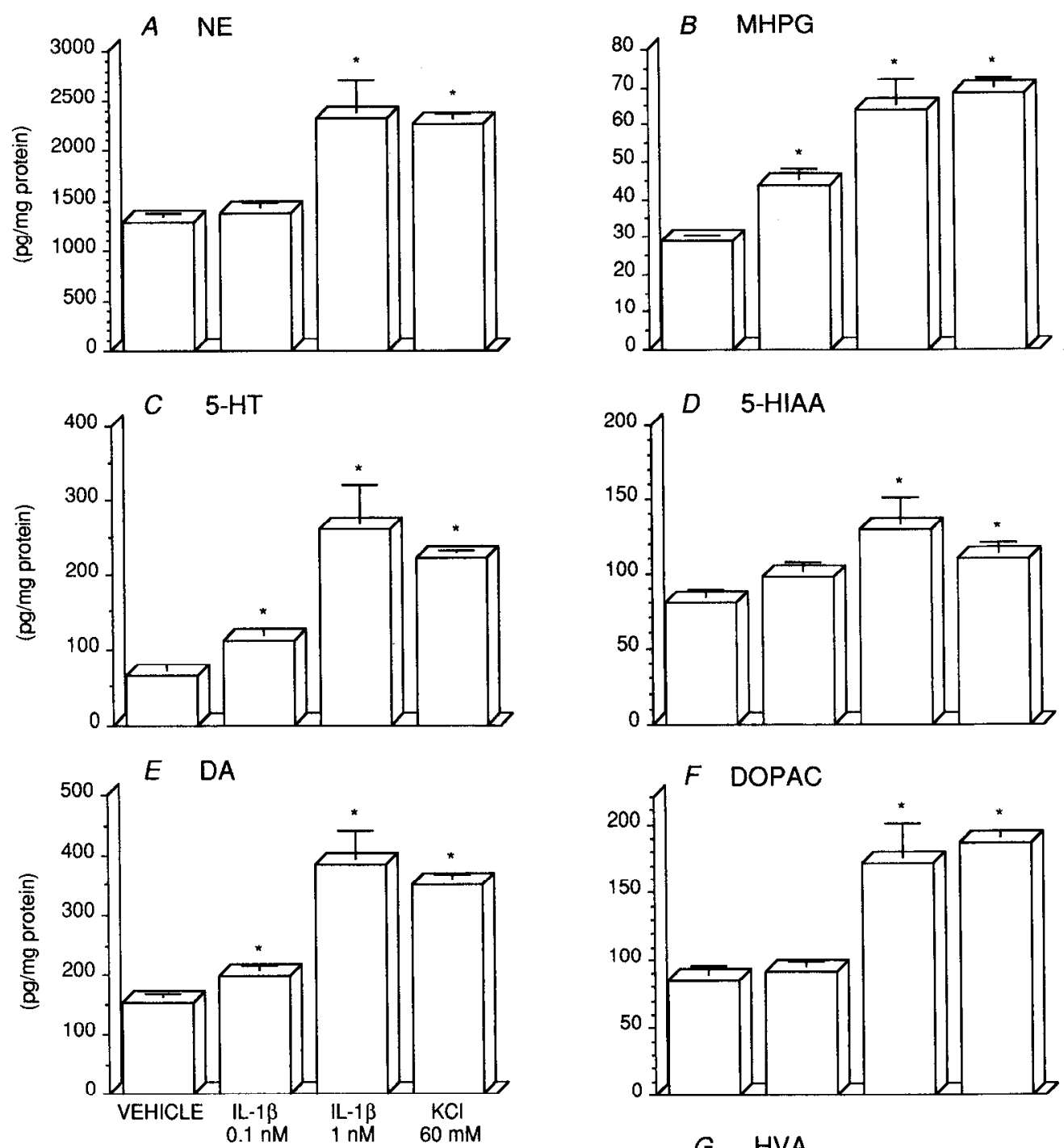

Figure 3. Effects of IL- $1 \beta$ on the levels of NE $(A)$, MHPG $(B)$, 5-HT $(C)$, 5-HIAA $(D)$, DA $(E)$, DOPAC $(F)$, and HVA $(G)$ released from rat hypothalamic slices. The IL- $1 \beta$ ( $1 \mathrm{nM})$-induced levcls of NE, MHPG, 5-HT, 5-HIAA, DA, DOPAC, and HVA were significantly higher than those induced by vehicle alone $\left(^{*}, P<0.05, n=4\right)$. Each value is the average $\pm \mathrm{SE}$ of four animals.

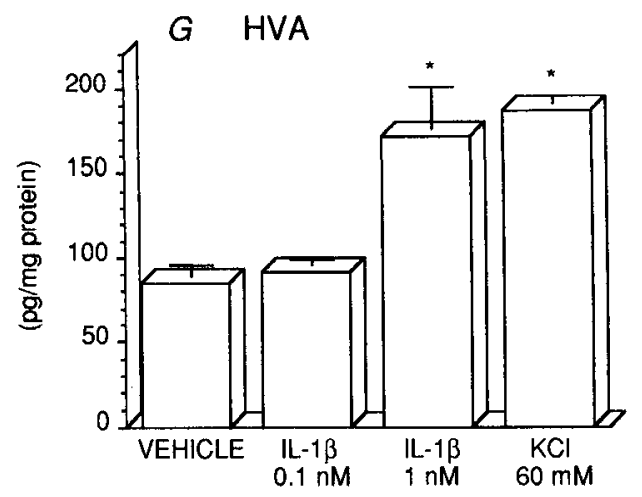

creased in the AHY. We also found that INDO significantly decreased the levels of 6-ketoprostaglandin $F_{1} \alpha$ in the rat hypothalamus and that, following direct administration of IL- $1 \beta$ into the AHY, the levels of 6-ketoprostaglandin $F_{1} \alpha$ could not be elevated. These observation show that the injected INDO had reached the hypothalamus at a sufficient concentration (Fig. $4 B)$.

\section{Effects of DXM administration on NE release}

Figure 5 shows that intraperitoneal administration of DXM $(0.3$ $\mathrm{mg} / \mathrm{kg}$, i.p.) or vehicle had no effects on basal release of NE. IL-
$1 \beta$ enhanced NE release irrespective of DXM administration. Administration of a lower dose of DXM $(0.03 \mathrm{mg} / \mathrm{kg}$, i.p. $)$ also had no effects on augmentation of NE release by IL-1 $\beta$ (data not shown). Intraperitoneal DXM $(0.3 \mathrm{mg} / \mathrm{kg})$ significantly decreased the levels of ACTH in the blood at 60 min postadministration (pre, $45.5 \pm 8.1 \mathrm{pg} / \mathrm{ml}$; post, $24.8 \pm 2.1 \mathrm{pg} / \mathrm{ml} ; P<$ $0.05 ; n=4$ ), indicating that injected DXM significantly inhibited CRH release from the hypothalamus. Administration of the DXM vehicle caused no significant changes in ACTH levels (pre, $48.0 \pm 10.3 \mathrm{pg} / \mathrm{ml}$; post, $44.1 \pm 6.6 \mathrm{pg} / \mathrm{ml} ; P>0.05 ; n$ $=4)$. 

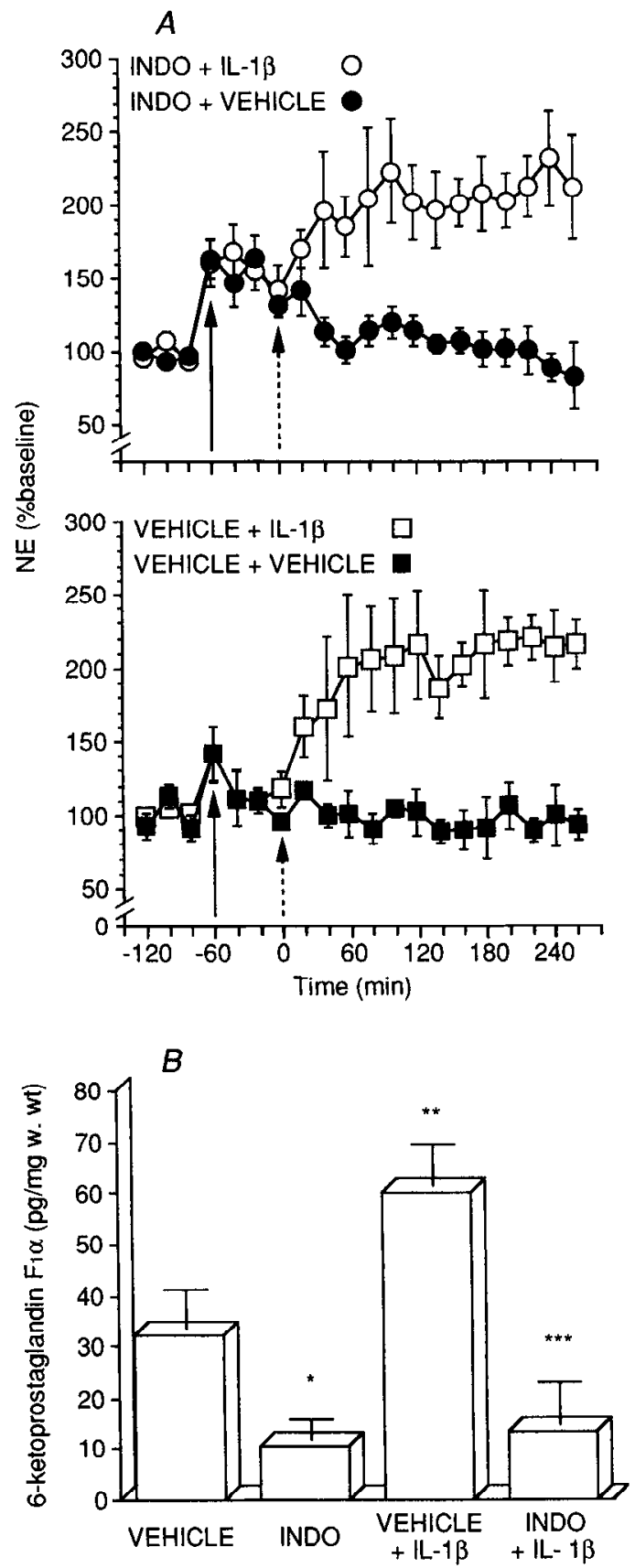

Figure 4. Effect of INDO pretreatment on IL-1 $\beta$-induced NE release in the rat AHY. $A$, INDO $(5 \mathrm{mg} / \mathrm{kg}$; open circles and solid circles) or vehicle $(3 \mathrm{ml} / \mathrm{kg}$; open squares and solid squares) was administered intraperitoneally at $60 \mathrm{~min}$ from the start of the experiment (solid arrows). Dialysis samples were collected every $20 \mathrm{~min}$ for $60 \mathrm{~min}$, for a total of three samples, and then IL-1 $\beta$ (1 ng/2 $\mu \mathrm{l}$; open symbols) or vehicle ( $2 \mu \mathrm{l}$; solid symbols) was injected (broken arrows). After IL-1 $\beta$ had been administered, the levels of NE increased significantly irrespective of INDO administration (open circles and solid circles: $P<$ $0.05, n=6$; open circles and open squares, $P>0.05, n=6$ ). $B$, Effect of INDO on the levels of 6-ketoprostaglandin $F_{1} \alpha$ in the hypothalamus. INDO $(5 \mathrm{mg} / \mathrm{kg})$ or vehicle $(3 \mathrm{ml} / \mathrm{kg})$ was injected intraperitoneally. IL$1 \beta(1 \mathrm{ng} / 2 \mu \mathrm{l})$ was administered directly into the bilateral AHY. INDO significantly decreased the level of 6-ketoprostaglandin $\mathrm{F}_{1} \alpha\left(^{*}, P<0.05\right.$, $n=4)$. While IL- $1 \beta$ administration, following preinjection of vehicle, induced elevation of 6-ketoprostaglandin $F_{1} \alpha$ in the hypothalamus $\left({ }^{* *}\right.$, $P<0.05, n=4)$, the INDO preinjection significantly inhibited IL-1 $\beta$ induced elevation of 6-ketoprostaglandin $\mathrm{F}_{1} \alpha\left({ }^{* * *}, P<0.05, n=4\right)$. Each value is the average \pm SE of four animals. Unit of the ordinate is picograms per milligram wet weight of the dissected hypothalamus.

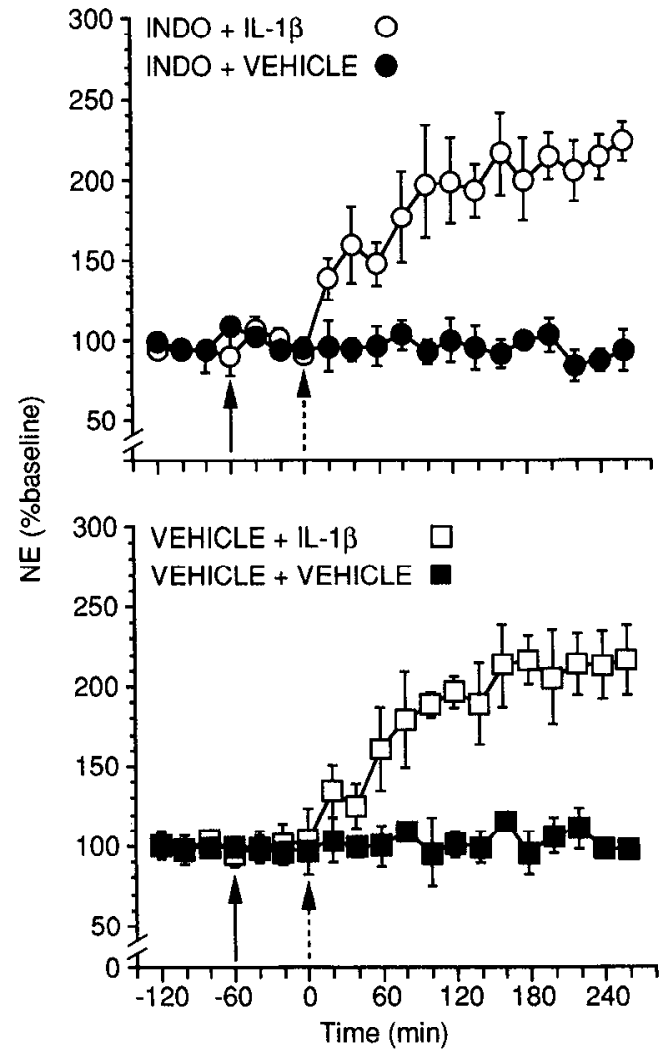

Figure 5. Effect of DXM on IL- $1 \beta$-induced NE release from the AHY. DXM $(0.3 \mathrm{mg} / \mathrm{kg}$; open circles and solid circles $)$ or vehicle $(3 \mathrm{ml} / \mathrm{kg}$; open squares and solid squares) was administered intraperitoneally at $60 \mathrm{~min}$ from the start of the experiment (solid arrows). Three dialysis samples were collected at $20 \mathrm{~min}$ intervals, and then IL- $1 \beta(1 \mathrm{ng} / 2 \mu \mathrm{l}$; open symbols) or vehicle $(2 \mu \mathrm{l}$; solid symbols) was injected (broken arrows). IL-1 $\beta$ delivered to the AHY through the microinjection tube induced significant NE release irrespective of the amount of DXM (open circles and solid circles: $P<0.05, n=6$; open circles and open squares: $P>0.05, n=6$ ).

\section{Discussion}

We have shown, by means of brain microdialysis using a novel microdialysis probe with an attached microinjection tube (Fig. $2 A-G)$, that IL-1 $\beta$ injected directly into the rat AHY increases extracellular levels of monoamines (NE, DA, and 5-HT) and their metabolites (MHPG, DOPAC, HVA, and 5-HIAA) at the site of injection. These results, which proved the increased levels of monoamines concomitant with the increased levels of their metabolites, suggest that the increased levels of monoamines are likely due to an increase in the release of the monoamines, rather than inhibition of monoamine reuptake, because other report showed that administration of reuptake inhibitor including fluoxetine increased the extracellular levels of 5-HT, but decreased the extracellular levels of 5-HIAA (Perry and Fuller, 1992).

We observed that IL- $1 \beta$ continuously enhanced the release of NE and DA in the AHY, but only transiently augmented 5-HT levels (Fig. $2 A, C, E$ ). It is difficult to explain these differences. Furthermore, sustained catecholamine release may not be due solely to a direct effect of IL- $1 \beta$, since we cannot exclude the possibility that IL- $1 \beta$ facilitated the production of other factors capable of inducing the continuous release of catecholamines. On the other hand, the IL- $1 \beta$-stimulated transient re- 
lease of 5-HT may be associated with elevation of cerebral tryptophan concentrations throughout the brain (Dunn, 1988; $\mathrm{Ka}$ biersch et al., 1988; Dunn and Welch, 1991). We cannot, however, ascertain whether this effect is attributable to any other factors, which might suppress the continuous release of 5-HT, or the IL- $1 \beta$ itself promoting the transient release of $5-\mathrm{HT}$.

These results raise two possibilities as to the mechanisms involved in IL- $1 \beta$-elicited monoamine release. First, IL- $1 \beta$ may directly affect neurons in the AHY to induce the release of these monoamines. This theory is supported by the existence of IL$1 \beta$ receptors on neurons in the rat hypothalamus (Katsuura et al., 1988). An alternative possibility is that IL- $1 \beta$ activates neurons in other regions, which then induce monoamine release. For example, since IL- $1 \beta$ is known to elicit release and production of CRH in the median eminence near the hypothalamus (Ovadia et al., 1989; Rivier et al., 1989; Barbanel et al., 1990; Saphier and Ovadia, 1990; Suda et al., 1990; Watanobe et al., 1991), and direct infusion of CRH into the locus coeruleus (LC) increases central and peripheral levels of catecholamines and their metabolites (Moore and Bloom, 1979; Foote et al., 1983; Valentino et al., 1983; Valentino and Wehby, 1988; Melia and Duman, 1991), it is possible that IL- $1 \beta$ enhances the levels of $\mathrm{NE}$ in the AHY by mediating the activation of LC neurons.

To ascertain whether or not the augmentation of monoamine release is derived from direct actions of IL- $1 \beta$ in the AHY, we performed slice experiments. When an hypothalamus slice was exposed to IL- $1 \beta$ in vitro, all monoamine levels increased (Fig. $3 A-G)$. Since their metabolites were also elevated in parallel, it may be assumed that this effect of IL-1 $\beta$ is explained by facilitation of release of these monoamines. These results support the contention that IL- $\beta$ acted on the AHY, rather than other regions, to enhance the release of monoamines in the microdialysis experiments.

The effects of administered IL- $1 \beta$ on monoamine release are controversial, but the route of administration may be an important factor altering the appearance of IL-1 effects, as discussed by Dunn and Chuluyan (1992). Since it has been shown that systemic administration of IL- 1 can enter throughout the brain (Banks et al., 1991), peripheral administered IL-1 $\beta$ may also reach the hypothalamus. However, investigators may have to consider other indirect effects, when IL- $1 \beta$ is injected intravenously, intraperitoneally, and even intracerebroventricularly, in studies of in vivo responses to IL-1. To examine the direct effects of IL- $1 \beta$ in the hypothalamus, we administrated it directly into the AHY. We speculate that the effects of intrahypothalamic IL- $1 \beta$ may not differ from those of systemic IL- $1 \beta$ as regards the monoamine lurnover-enhancing effects of IL- $1 \beta$.

Since IL-1 may induce the production of various other factors with neurological effects, we cannot ascertain the direct actions of IL- $1 \beta$ on neurotransmitter release. However, prostaglandins (PGs) seem to be one of the more likely intermediate as candidates, because IL- $1 \beta$ increases prostaglandin $E_{2}$ in rat astrocyte cultures (Katsuura et al., 1989), and the IL-1-induced ACTH response is mediated by $\mathrm{CRH}$ secretion stimulated by hypothalamic prostaglandin E (Watanabe et al., 1990). Furthermore, the increases in MHPG and 5-HIAA observed following systemic administration of IL-1 were antagonized by concurrent administration of INDO (Mefford and Heyes, 1990), and the effects of IL- 1 on hypothalamic MHPG content and NE turnover were also blocked by INDO (Masana et al., 1990). These reports suggest that the increases in NE, DA, and 5-HT release induced by IL- $1 \beta$ in the hypothalamus are partially mediated by the actions of arachidonic acid metabolites. However, Dunn et al. (1992) recently reported that pretreatment of mice with INDO failed to prevent the elevation of hypothalamic MHPG that follows intraperitoneal administration of $\mathrm{LL}-1$.

Our results also suggest that direct administration of IL-1 $\beta$ into the AHY increases the levels of PGs, and that these increases are inhibited by INDO pretreatment (Fig. $4 B$ ). As shown in Figure $4 A$, however, IL- $\beta$ can enhance the release of NE under the condition where the formation of 6-ketoprostaglandin $\mathrm{F}_{1} \alpha$ was inhibited by pretreatment with INDO, suggesting that IL- $1 \beta$ alone can directly enhance the release of NE without the involvement of PG production in the AHY. In addition, this result also suggests that the effects of intrahypothalamic IL-1 $\beta$ may differ from those of systemic IL- $1 \beta$. We suppose that the discrepancies about the roles of PG may not be due to the difference of administration route or animals concerning the results of Dunn et al. (1992).

Since CRH may also be an intermediate in the IL- $1 \beta$-induced release of monoamines, we determined whether administering IL- $1 \beta$ directly into the AHY would promote the release of NE in the same region when $\mathrm{CRH}$ release has been inhibited by pretreatment with large amounts of DXM. As shown in Figure 5 , NE levels increased in the AHY, despite significantly reduced levels of plasma ACTH. This result suggests that IL- $1 \beta$ injected directly into the AHY can induce the release of NE in the hypothalamus even when CRH levels are low. Other reports have demonstrated that DXM treatment significantly inhibits IL-1stimulated CRH release (Cambronero et al., 1989; Bernardini et al., 1990). We cannot, however, deny that DXM directly affected the pituitary gland to inhibit release of ACTH.

In light of our results and those of other investigators, we conclude that IL- $1 \beta$ in the AHY may be capable of inducing the release of NE directly without involvement of PGs or CRH.

It is well known that some forms of stress-induced activation of the HPA axis can overcome the preventive effects of DXM (Dallman and Yates, 1968; Takebe et al., 1971). Some investigators have tried to explain this phenomenon from the following results. The elevated levels of $\mathrm{NE}$ in the hypothalamus affect the pituitary gland to promote the release of ACTH (Lamberts et al., 1986). DXM cannot completely abolish the ACTH release induced by the combined action of CRH and NE (Bilezikjian and Vale, 1983; Giguère and Labrie, 1983; Lamberts et al., 1986). It is also well known that IL-1 can elicit acceleration of the HPA axis (Berkenbosch et al., 1987; Sapolsky et al., 1987). Weidenfeld et al. (1989) suggested that IL-1 may activate the adrenocortical axis, at least in part, by interfering with the negative feedback effect of circulating glucocorticoids, Morcover, it is known that immobilization stress induces IL- $1 \beta$ mRNA in the rat hypothalamus (Minami et al., 1991).

These results raise a possibility that activation of the HPA axis induced by a stress load such as immobilization is due to overproduction of IL- $1 \beta$ in the hypothalamus. Considering that IL- $1 \beta$ can induce the release of NE from the AHY despite preadministration of a large dose of DXM, IL- $1 \beta$ may promote the release of ACTH by overcoming the suppressive effects of DXM. We would like to propose the possibility that there is an alternative pathway mediating stress-induced activation of the HPA axis, one that involves a factor with the following characteristics. First, it can be induced by a stress load. Second, it can increase NE release in the hypothalamus. Third, its NE-releasing actions are not inhibited by DXM. Although our results also suggest that hypothalamic IL- $1 \beta$ is likely to play a role in the regulation 
of stress reactions including NE turnover and the HPA axis, whether IL $-1 \beta$ is a main regulator remains to be clarified.

\section{References}

Banks WA, Ortiz L, Plotkin SR, Kastin AJ (1991) Human interleukin (IL) $1 \alpha$, murine IL- $1 \alpha$ and murine IL- $1 \beta$ are transported from blood to brain in the mouse by a shared saturable mechanism. J Pharmacol Exp Ther 259:988-996.

Barbanel G, Ixart G, Szafarczyk A, Malaval F, Assenmacher I (1990) Intrahypothalamic infusion of interleukin-1 beta increases the release of corticotropin-releasing hormone (CRH 41) and adrenocorticotropic hormone $(\mathrm{ACTH})$ in free-moving rats bearing a push-pull cannula in the median eminence. Brain Res 516:31-36.

Berkenbosch F, Oers JV, del Rey A, Tilders F, Besedovsky H (1987) Corticotropin-releasing factor-producing neurons in the rat activated by interleukin-1. Science 238:524-526.

Berkenbosch F, Wolvers DA, Derijk R (1991) Neuroendocrine and immunological mechanisms in stress-induced immunomodulation. J Steroid Biochem Mol Biol 40:639-647.

Bernardini R, Calogero AE, Mauceri G, Chrousos GP (1990) Rat hypothalamic corticotropin-releasing hormone secretion in vitro is stimulated by interleukin- 1 in an eicosanoid-dependent manner. Life Sci 47:1601-1607.

Besedovsky HO, del RA, Klusman I, Furukawa H, Monge AG, Kabiersch A (1991) Cytokines as modulators of the hypothalamuspituitary-adrenal axis. J Steroid Biochem Mol Biol 40:613-618.

Bilezikjian LM, Vale W (1983) Glucocorticoids inhibit corticotropinreleasing factor-induced production of adenosine $3^{\prime}, 5^{\prime}$-monophosphate in cultured anterior pituitary cells. Endocrinology 113:657-662.

Cambroncro JC, Borrcll J, Guaza C (1989) Glucocorticoids modulate rat hypothalamic corticotrophin-releasing factor release induced by interleukin-1. J Neurosci Res 24:470-476.

Carmelina G, Pietro G, De Simoni MG (1991) Activation of the hypothalamic serotoninergic system by central interleukin-1. Eur J Pharmacol 209:139-140.

Dallman MF, Yates FE (1968) Anatomical and functional mapping of central neural input and feedback pathways of the adrenocortical system. In: Memoirs of the Society for Neuroscience, No 17 (James VHT, Landon J, eds), pp 39-71. London: Cambridge UP.

Dunn AJ (1988) Systemic interleukin-1 administration stimulates hypothalamic norepinephrine metabolism paralleling the increased plasma corticosterone. Life Sci 43:429-435.

Dunn AJ, Chuluyan HE (1992) The role of cyclo-oxygenase and lipoxygenase in the interleukin-1-induced activation of the IIPA axis: dependence on the route of injection. Life Sci 51:219-225.

Dunn AJ, Welch J (1991) Stress- and endotoxin-induced increases in brain tryptophan and serotonin metabolism depend on sympathetic nervous system activity. J Neurochem 57:1615-1622.

Dunn AJ, Antoon M, Chapman Y (1991) Reduction of exploratory behavior by intraperitoneal injection of interleukin-1 involves brain corticotropin-releasing factor. Brain Res Bull 26:539-542.

Foote SL, Bloom FE, Aston-Jones G (1983) Nucleus locus ceruleus: new evidence of anatomical and physiological specificity. Physiol Rev 63:844-914.

Giguère V, Labrie F (1983) Additive effects of epinephrine and corticotropin-releasing factor (CRF) on adrenocorticotropin release in rat anterior pituitary cells. Biochem Biophys Res Commun 110:456462.

Gwosdow AR, Kumar MS, Bode HH (1990) Interleukin I stimulation of the hypothalamic-pituitary-adrenal axis. Am J Physiol 258:E65E70.

Kabiersch A, del Rey A, Honegger CG, Besedovsky HO (1988) Interleukin- 1 induces changes in norepinephrine metabolism in the rat brain. Brain Behav Immunol 2:267-274.

Katsuura G, Gottschall PE, Arimura A (1988) Identification of a highaffinity receptor for interleukin-1 beta in rat brain. Biochem Biophys Res Commun 156:61-67.

Katsuura G, Gottschall PE, Dahl RR, Arimura A (1989) Interleukin-1 beta increases prostaglandin $E_{2}$ in rat astrocyte cultures: modulatory effect of neuropeptides. Endocrinology 124:3125-3127.

Lamberts SWJ, Bons E, Zuiderwijk J (1986) High concentrations of catecholamines selectively diminish the sensitivity of CRF-stimulated effects of dexamethasone. Life Sci 39:97-102.
Lowry OH, Rosebrough NJ, Farr AL, Randall RJ (1951) Protein measurement with the folin phenol reagent. J Biol Chem 193:265275.

Masana MI, Heyes MP, Mefford IN (1990) Indomethacin prevents increased catecholamine turnover in rat brain following systemic endotoxin challenge. Prog Neuropsychopharmacol Biol Psychiatry 14: 609-621.

Mefford IN, Heyes MP (1990) Increased biogenic amine release in mouse hypothalamus following immunological challenge: antagonism by indomethacin. J Neuroimmunol 27:55-61.

Melia KR, Duman RS (1991) Involvement of corticotropin-releasing factor in chronic stress regulation of the brain noradrenergic system. Proc Natl Acad Sci USA 88:8382-8386.

Minami M, Kuraishi Y, Yamaguchi T, Nakai S, Hirai Y, Satoh M (1991) Immobilization stress induces interleukin-1 beta mRNA in the rat hypothalamus. Neurosci Lett 123:254-256.

Mohankumar PS, Thyagarajan S, Quadri SK (1991) Interleukin-1 stimulates the release of dopamine and dihydroxyphenylacetic acid from the hypothalamus in vivo. Life Sci 48:925-930.

Moore RY, Bloom FE (1979) Central catecholamine neuron systems: anatomy and physiology of the norepinephrine and epinephrine systems. Annu Rev Neurosci 2:113-168.

Nakai Y, Kawamura H, Yamamoto M, Ooe Y, Hukada J, Kawamura H (1989) Clinical experience with ACTH IRMA kit Mitubishiyuka for the measurement of adrenocorticotropic hormone (ACTH). J Med Pharm Sci 22:171-179.

Nakaki T, Saito M, Nakadate T, Tokunaga Y, Kato R (1981) Acute physical dependence induced by continuous intravenous infusion of morphine or meperidine in the rat. Psychopharmacology 73:215-218.

Ovadia H, Abramsky O, Barak V, Conforti N, Saphier D, Weidenfeld J (1989) Effect of interleukin-1 on adrenocortical activity in intact and hypothalamic differentiated male rats. Exp Brain Res 76:246249.

Palazzolo DL, Quadri SK (1990) Interleukin-1 stimulates catecholamine release from the hypothalamus. Life Sci 47:2105-2109.

Perry KW, Fuller RW (1992) Effect of fluoxetine on serotonin and dopamine concentration in microdialysis fluid from rat striatum. Life Sci 50:1683-1690.

Rivier C, Vale W, Brown M (1989) In the rat, interleukin-1 alpha and -beta stimulate adrenocorticotropin and catecholamine release. Endocrinology 125:3096-3102.

Saphier D, Ovadia H (1990) Selective facilitation of putative corticotropin-releasing factor-secreting neurones by interleukin- 1 . Neurosci Lett 114:283-288.

Sapolsky R, Rivicr C, Yamamoto G, Plotsky P, Vale W (1987) Interleukin-1 stimulates the secretion of hypothalamic corticotropinreleasing factor. Science 238:522-524.

Suda T, Tozawa F, Ushiyama T, Sumitomo T, Yamada M, Demura H (1990) Interleukin-1 stimulates corticotropin-releasing factor gene expression in rat hypothalamus. Endocrinology 126:1223-1228.

Takebe K, Kunita H, Sakakura M, Horiuchi Y, Mashimo K (1971) Suppressive effect of dexamethasone on the rise of CRF activity in the median eminence induced by stress. Endocrinology 89:1014-1019.

Tsagarakis S, Gillies G, Rees LH, Besser M, Grossman A (1989) Interleukin-1 directly stimulates the release of corticotropin releasing factor from rat hypothalamus. Neuroendocrinology 49:98-101.

Valentino RJ, Wehby RG (1988) Corticotropin-releasing factor: evidence for a neurotransmitter role in the locus ceruleus during hemodynamic stress. Neurocndocrinology 48:674-677.

Valentino RJ, Foote SL, Aston-Jones G (1983) Corticotropin-releasing factor activates noradrenergic neurons of the locus coeruleus. Brain Res 270:363-367.

Watanabe T, Morimoto A, Sakata Y, Murakami N (1990) ACTH response induced by interleukin- 1 is mediated by CRF secretion stimulated by hypothalamic PGE. Experientia 46:481-484.

Watanobe H, Sasaki S, Takebe K (1991) Evidence that intravenous administration of interleukin-1 stimulates corticotropin releasing hormone secretion in the median eminence of freely moving rats: estimation by push-pull perfusion. Neurosci Lett 133:7-10.

Weidenfeld J, Abramsky O, Ovadia H (1989) Effect of interleukin-1 on $\mathrm{ACTH}$ and corticosterone secretion in dexamethasone and adrenalectomized pretreated male rats. Neuroendocrinology 50:650-654. 